Entrevista - Diálogos Midiológicos 32

\title{
Tendências do Jornalismo Esportivo na visão de Antonio Alcoba Lopez
}

Sports Journalism's tendencies to Antonio Lopez Alcoba

Tendencias del Periodismo Deportivo en la visión de Antonio López Alcoba

DOI: $10.1590 / 1809-58442015216$

Antonio Alcoba Lopez

(Universidad Complutense de Madrid, Facultad de Ciencias de la Información, Departamento de Estructura de la Infomación, Madri, Espanha)

Entrevista concedida a Marli Hatje

(Universidade Federal de Santa Maria, Centro de Educação Física e Desportos, Departamento de Métodos e Técnicas Desportivas. Santa Maria - RS, Brasil)

decisão de registrar em texto
as experiências e vivências $\mathcal{L}$ de um dos maiores nomes do Jornalismo Esportivo mundial, se não o maior, aconteceu quando visitei o professor Antonio Alcoba Lopes, 77 anos, pela terceira vez em Espanha, em abril de 2011.

Quem conhece pessoalmente o prof. Alcoba o admira pessoal

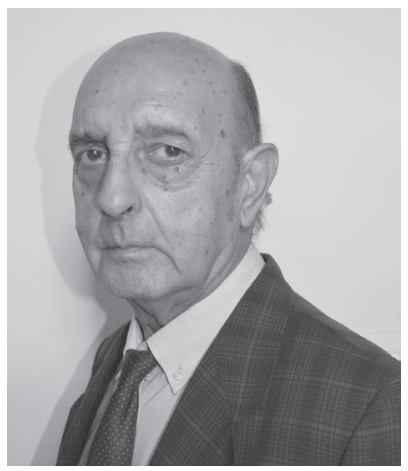


e profissionalmente. É de uma simplicidade, cordialidade e humanidade impressionante. Com 45 anos de experiência profissional já influenciou e continua influenciando gerações de jornalistas que tem no esporte e no Jornalismo, como ele, suas grandes paixões. Raros são os trabalhos sobre o Jornalismo especializado na área do esporte, no Brasil, que não citam suas obras nas referências bibliográficas básicas.

Conheci pessoalmente o prof. Alcoba, em 2000, em Santa Maria, RS, quando veio ao Brasil, pela segunda vez, para compor a banca de minha tese intitulada Grande imprensa: valores e características veiculadas por jornais brasileiros para descrever a participação da seleção brasileira de futebol na Copa do Mundo de 1998 na França. A primeira vez, em 1976, esteve no Rio de Janeiro, com a Seleção Espanhola de Hockey.

De lá para cá, nossos contatos acadêmicos se fortaleceram e ele passou a ser um motivador e orientador das minhas jornadas acadêmicas e profissionais. $O$ convite para participar da primeira edição do Curso de Jornalismo Esportivo, da Universidade Federal do Rio Grande do Sul, em janeiro de 2012, em Porto Alegre, foi aceito, porém, problemas de saúde o impediram de vir ao Brasil.

Nesta entrevista, o prof. Alcoba conta sua trajetória de vida, que começou em maio de 1935, em Madrid. Relata, de forma clara e objetiva, como jornalista experiente, os principais fatos que marcaram sua vida, a de seu público, principalmente leitores e apreciadores das inúmeras exposições fotográficas esportivas, de seus alunos na Universidade Complutense de Madrid e ainda seus seguidores, os jornalistas e estudiosos do Jornalismo especializado na área esportiva em todo mundo.

O prof. Alcoba nasceu no dia 4 de maio de 1935 em Madrid, Espanha. É filho de Dolores e Luis. É casado com Manuela Sancho Rodríguez (Manoli) e tem dois filhos, Mónica e Antonio e dois netos, Antonio e Irene.

Dos 30 livros publicados, nove tratam especificamente sobre Mídia e esporte. Porém, praticamente todos reportam-se ao esporte, sua grande paixão (ver tabela no fim da entrevista). Durante duas décadas organizou inúmeros Seminários sobre 
Informação Esportiva, sendo este considerado o evento mais antigo da Espanha.

Foi um dos primeiros jornalistas a escrever sobre a importância e os valores do esporte escolar e o desenvolvimento no âmbito universitário.

Sua vida acadêmica, na Universidade Complutense de Madrid, começou em 1973 quando ingressou na Facultad de Ciencias de la Información. Em 1978, ao concluir o curso apresentou o estudo Estructura del periodismo deportivo, que lhe rendeu uma vaga como bolsista no Departamento de Estructura de la Infomación. Sua tese, apresentada em 1984, intitulada Deporte y Comunicación, foi publicada em forma de livro em 1987.

Pelo exposto, mas principalmente pelo que ele representa ao cenário esportivo midiático mundial, acredito que o empenho em conversar longamente com o prof. Alcoba, durante um ano, valeu a pena, não só para meu crescimento profissional e de meu grupo de estudo na Universidade Federal de Santa Maria, mas porque as respostas são importantes subsídios para discussões e reflexões acadêmicas e profissionais em todo Brasil, principalmente pelo fato de o país ter sido sede da Copa do Mundo de 2014 e estar se preparando para receber os Jogos Olímpicos em 2016.

Com o objetivo de manter a originalidade da entrevista, as respostas estão em língua espanhola.

Revista Intercom - No Brasil, o senhor é considerado uma grande referência, se não a maior, no Jornalismo esportivo. Para iniciarmos nossa entrevista, gostaria que o senhor resumisse sua trajetória de vida. Antonio Alcoba - En breve resumen de mi curriculum puedo añadir, que he sido vicepresidente de la Asocación Hispanoamérica de Reporteros Gráficos, en el Congreso de de México, presidente de la Asociación Española de Periodistas Olímpicos, y vicepresidente de la Agrupación Española de Periodistas Deportivos. Entre otros galardones, al margen de los ya citados, soy Medalla de la Juventud, Medalla de la Universidad Complutense de Madrid, Premio de Honor de la Agrupación Española de Periodistas Deportivos, Premio Larra de la Unión de Periodistas, Medalla de 
Oro de la ANIGP, Trofeo Homenaje del Festival Internacional de Periodismo Deportivo de Santander, 4o Premio del Asahi Pentax World Contest, de japón y $1^{\mathrm{o}}$ deportivo de dicho concurso. Tengo cinco diplomas en la World Press Photo, de Holanda, Primer Premio del Concurso Internacional de artículos de prensa sobre el Campeonato del Mundo de Fútbol de España en 1982 y Primer premio del Concurso Nacional de fotografía sobre el mecionado campeonato, Primer Premio del certamen madrileño de Fotografía deportiva etc. También he realizado las siguientes exposiciones individuales: II Juegos Atléticos Iberoamericanos, Madrid, Feria Mundial de Nueva York, Nueva York, Fotografía deportiva, Madrid, 1957- 1967 (I), Madrid, 1957-1967 (II) Retratos periodísticos (I), Retratos periodñisticos (II), Nueva York sin las Torres Gemelas, Fútbol, Homenaje a Nueva York, y Oficios y profesiones en el Madrid del siglo XX. He pronunciado conferencias sobre Periodismo deportivo y Periodismo en la Universidad del Sagrado Corazón, de San Juan; Universidad Autónoma de San Juan y Universidad Autónoma de Ponce, en Puerto Rico, en la Asocciación de periodistas deportivos de Perú, en Lima, en la Universidad de Arequipa y en diversas universidades españolas. Dirigí el taller de Periodismo de la Rura Quetzal, en 1993.

Revista Intercom - Na sua vida pessoal, antes de ingressar na carreira de jornalista, há fatos e experiências que justificam seu interesse ou a vocação para a área, inclusive, a esportiva? Ou seja, quando criança e jovem, o senhor era um desportista?

Alcoba - Por culpa de la Guerra Civil española, que nos llevó a una mísera posguerra, a los 12 años comence a trabajar como recadero de una Droguería-Perfumería, desde mi niñez fue un crío con criterio propio y de ese trabajo en el que me explotaban, pasé a una corsetería de la que por el mismo caso, me despedí para trabajar en una tienda de artículos de fumador. Posteriormente, pase a trabajar de aprendiza en un taller de gatos hidraúliscos para automóviles y limpiar coches para por ultimo entrar en el diario Arriba, que de órgano de Falange Española de las JONS, había pasado a ser el periòdico oficial del franquismo, en calidad 
de botones. Allí, como bien destacas, comenzó mi afición por el Periodismo, ya que mis ratos libres los pasaba en la maravillosa biblioteta del diario, que había pertenecido al diario republicano El Sol y La Voz.

Revista Intercom - Então o senhor começou sua carreira como autodidata e na função de auxiliar de fotógrafo?

Alcoba - El fotógrafo del Periódico José Pastor me dio pie para que en mis ratos libres le ayudase en su trabajo. Más adelante pase a la sección de fotografía del taller de huecograbado y fue entonces cuando con mucho sarificio adquirí un cámara Regula y una ampliadora, para desde ese momento hacer mis propias fotografías. Durante unos años en los que combiné el trabajo del taller con la fotografía de prensa y olaborés con los periódicos madrileños ABC, Ya, Informaciones y Diario Madrid, del que fui un asiduo colaborador durante varios años. Según fui adquiriendo calidad periodística en mis fotografías mi labor de free-lance, se fue acredcentando y comenzé a colaborar con las grandes de revistas españolas Gaceta Ilustrada, Blanco y Negro, Actualidad Española, y otras muchas. En esa época ya era un reputado fotógrafo en todas las ramas, especialmente en la deportiva. Mi popularidad en los medios españoles me llevaron a trabajar en la Agencia Europa Press y AS Press, ampliar mi cartera de trabajo a otros sectores, si bien no abandone mi trabajo en el taller de fotografía de huecograbado, pues aquello era un trabajo seguro. En los años 60 del pasado siglo, conseguí que una fotografía mía fuese seleccionado por la Delegación Nacional de Deportes, y se expuso en la Mostra Fotográfica de los Juegos Olímpicos de Roma de 1960, donde se me concedió medalla y diploma olímpico. En 1961, en la exposición fotográfica para conmemorar el IV aniversario de la Capitalidad de Madrid, obtuve el Premio de Honor del Circulo de Bellas Artes y primero del concurso. Eso elevó mi categoría.

Revista Intercom - Entre suas experiências profissionais significativas, o senhor destaca sua participação como membro da Imprensa Oficial Espanhola? Qual era sua função neste Órgão? 
Alcoba - En 1964, me ofrecieron acudir a la Feria Mundila de Nueva York, integrándome en el Gabinet de Prensa del Pabellón de España, y allí acudí. En Nueva York, me acredité como corresponsal del diario Arriba en Naciones Unidas y asistí a la Asamblea General, los debates del Consejo de Seguridad y sobre todo, al debate, en el Comité de los 24, sobre Gibraltar, cuyas imágenes se publicarón en exclusiva en el diario Arriba en España y fueron dufundidas a través de muchos diarios y revistas. Envíe a España innumerables reportajes de esa ciudad. Al finalizar la primera etapa de la Feria, realicé en Madrid una exposición de 250 fotografías, la mayor realizada a título individual en España y pasé a formar parte de la revista Triunfo. Acudí al segundo périodo de la Feria y tuve contactos con las grandes figuras políticas, intelectuales y artísticas españolas y extranjeras de aquella época, entre ellas el que había sido vicepresidente de los Estados Unidos y que años más tarde fue presidente, Richard Nixon, el alcalde de Nueva York Robert Wagner, el premio nobel español Severo Ochoa, el pintor Salvador Dalí, el actor Mario Moreno Cantinflas - Charlton Heston, el doctor Castro Viejo, el representante español en la ONU Manuel Aznar, y el embajador Jaime de Pinies, artistas como Antonio Gades, en fin, un largo etcétera. Fui el único periodistas que asistió a la presentación de dossier de auto-determinación del Sahara Español y a la visita del Papa Pablo VI a la ONU.

Revista Intercom - Em 1967, há 45 anos, portanto, o senhor ingressou definitivamente no Jornalismo esportivo. É nesta fase que também foi publicado seu primeiro livro na área chamado icontamos contigo? Alcoba - A mi regreso a España trabajé para el diario Pueblo y luego para el Diario Informaciones hasta que, en 1967, me llamaron para hacerlo en un nuevo periódico deportivo, el Diario Gráfico Deportivo As, del que, por tanto, soy fundador, así como de la revista As-Color. Fue ese un periodo fecundo, donde alterné los reportajes gráficos con los literarios, pero también problemáticos, la censura que se hacía a mis crónicas de atletismo, me llevaron a negarme a escribir de este deporte, por lo que el redactor 
jefe me encargo de los deportes minoritarios, y la dirección no me impidió que mi tarea de comentaristas de atletismo la realizase en el el diario Pueblo. En esa época fue cuando funde mi revista mensual de atletismo Pista y Campo, con la que atravesé momentos dulces y amargos, especialmente porque al convertirme en el periodista crítico de los métodos en que se llevaba el atletismo, la federación española impidió que me llegasen anuncios de las firmas deportivas, sob pena de no comprarles sus artículos. La publicación con grandes sacrificios económicos pude mantenerla durante 20 números, entre 1972 y 1973. Este último años apareció mi primer libro deportivo, ¿Contamos Contigo?, slogan de la Delegación Nacional de Deportes, cuyo texto fue censurado en más de la mitad de sus 300 páginas. Al negarme a reformarlo el editor publicó el libro sin tachaduras y no pasó absolutamente nada. Durante los años de la transición polìtica en España, formé parte de un grupo de periodistas gráficos que luchábamos por el reconocimiento de nuestra profesión, creando la Asociación Nacional de Informadores Gráficos de Prensa de España (ANIGP), que agrupó a los fotógrafos y cámaras de televisión. En la primera junta directiva fui elegido vicepresidente y, en 1986, presidente por un periodo de cuatro años. Al cumplirlo, pretendí dejarlo pero mis compañeros me pidieron que continuase, lo que hice por otro año.

Revista Intercom - Na Faculdade de Ciências da Informação, em 1978, o senhor desenvolveu o trabalho intitulado Estrutura do Periodismo Deportivo e, posteriormente, em 1984, apresentou sua tese intitulada Deporte y Comunicación, um livro importante para os profissionais que atuam no Jornalismo esportivo, inclusive, no Brasil. Como foi essa experiencia de relacionar conhecimentos acadêmicos e empíricos?

Alcoba - En 1973, ingresé en la Facultad de Ciencias de la Información de la Universidad Complutense de Madrid. En 1978, convertirme en becario del Departamento de Estructura de la Información del Catedrático Pedro Orive Riva. También en 1978 lei mi tesis doctoral, titulada Deporte y Comunicación. 


\section{TENDÊNCIAS DO JORNALISMO ESPORTIVO \\ NA VISÃO DE ANTÔNIO ALCOBA LOPEZ}

Como anécdota, debo señalar que ante las cosas que me señaló en tribunal, les repliqué que respetando sus opiniones, no las compartía, entre otras cosas porque de cuanto estábamos en la sala, el que más conocimiento del deporte era yo. No les sentó muy bien al tribunal mi aclaración pero me otorgaron el sobresaliente cum laude. En el posterior almuerzo, me comentaron que los juzgados habían sido ellos y yo el tribunal. Afortunadamente, todo quedo en esta anécdota. A partir de ese año, comencé a celebrar unos seminarios deportivos, que tuvieron tal aceptación que el director del Departamento consideró que debía pasarlos a la categoría de curso anual. En tanto ese se conseguía impartí clases en el Instituto Nacional de Educación Física y Deportes de Madrid. El curso Deporte y Comunicación ha sido el más longevo de toda la Universidad Española, 25 años initerrumpidos y por el que pasaron 38.400 alumnos, 82 personalidades y dirigentes, de ellas 23 extranjeras, 96 deportistas, 145 periodistas: 37 melladistas olímpicos, 12 campeones del mundo, cinco campeones de Europa, 18 seleccionadores nacionales, dos vencedores de la Vuelta Ciclista a Francia, cuatro de la Vuelta Ciclista a España, dos vencedores del Torneo Rolanda Garros y uno del Open Usa y Wimbledom. En 1998, el Instituto Universitario Olímpico de Ciencias de Deporte me encargó la dirección del I Curso de Periodismo Deportivo abierto a los alumnos de la Universidad Complutense y otras Universidades madrileñas

Revista Intercom - Em 1986, com as mudanças estruturais e políticas no Diário AS, o senhor deixou o periódico após 20 anos de atividades na empresa e passou a se dedicar exclusivamente às atividades da Universidade. Como foi esse período de transição de um jornal diário para uma instituição de ensino superior?

Alcoba - En el año 1986, al pasar la empresa editora del Diario Gráfico Deportivo As a manos de los hijos del dueño, estos se empeñaron en reducir gastos en la forma de hacernos imposible la vida a los redactores, para despidiendo a los veteranos contratar mano de obra barata através de becarios. El individuo designado para dirigir esta operación fue un socialista llamado Julián García 
Candau, que tuvo el honor de recoger un periódico sin ningún tipo de renovación tecnológica, pero con una tirada de $161 \mathrm{mil}$ ejemplares y que con su política de acoso y derribo al auténtico Periodismo deportivo, llegó al extremo de prohibir opinar a los redactores, cuando lo echaron por inútil, había dejado al periódico con una tirada de 84 mil ejemplares, y fue adquirido por la empresa periodística PRISA, que ahora tiene una tirada de $200 \mathrm{mil}$ ejemplares. Este individuo y los dos nietos del fundador del medio, en su afán por reducir personal veterano se inventaron, en mi caso que yo colaboraba con la revista del Comitè Olímpico Español, Olimpia, y que percibía por ello remuneraciones. La falsedad de aquella historia, fue refutada por el entonces presidente del COE, Carlos Ferrer Salat, puesto que tan sólo había realizado tres artículos y sin retribución. Pese a todo, me incoaron expediente grave para despedirme. En ese momento me encontraba en la lucha por conseguir la plaza de profesor titular con un compañero del Departamento, que gané con mi proyecto docente de tecnología de la información, sobre los medios especializados. Al obtener la plaza, opté por dejar As, tras casi 20 años de trabajo en ese medio. La UCM, una vez desvinculado del periódico, me encargo la jefatura de la página deportiva de la publicación de la Universidad, Gaceta Complutense, que ejercí durante diez años.

Revista Intercom - Considerando sua experiência com o Jornalismo especializado na área esportiva, como o senhor analisa o Jornalismo esportivo hoje em nível mundial?

Alcoba - El Periodismo deportivo ha pasado de ser un género periodístico distinto a otros a convertirse en producto de consumo, auspiciado por las empresas periodísticas como puro negocio capitalista que proporcione beneficios y, a su vez, pueda ser controlado por el poder político bajo las directrices del poder mediático capitalista. La proliferación de nuevos deportes, especialmente de riesgo o de aventura, se fomenta para que la industria del deporte - negocio puramente capitalista - atraiga a un número de practicantes y se vean obligados a comprar indumentaria y artículos para su práctica. Desde finales del 
siglo 20, el deporte no ha dejado de crecer con el apoyo de los políticos, quienes utilizan los éxitos de los deportistas como hazañas personales de sus diferentes ideologías para presentarlas, caso del presidente del Gobierno de España, Sr. Rodríguez, quien paseó por foros internacionales la Copa del Mundo de Fútbol de 2010, ganada por la selección española, como si fuese un triunfo suyo, de su Gobierno y partido político. Por su parte, los medios de Comunicación se aprovechan de esa situación y dedican la mayor parte de su espacio a los deportes espectáculo más profesionalizados y, junto política y capitalismo, hacer rentable el negocio informativo. En definitiva, el Periodismo deportivo ha comenzado a consolidarse como un género más similar al llamado género periodístico del corazón y del show televisivo y radiofónico que al deportivo, ya que ahora se inserta en el área del deporte todo tipo de aspectos sentimentales, económicos, curiosos de los deportistas, junto a la información exclusivamente deportiva. Ello permite que el Periodismo deportivo se olvide del deporte como deporte, para ya sin fisuras, dedicarse de lleno a la explotación del deporte espectáculo.

Revista Intercom - Comparando o Jornalismo esportivo de hoje com aquele praticado quando o senhor começou sua carreira, quais são as mudanças mais evidentes na sua opinião?

Alcoba - Como en todos los sectores del Periodismo, el tratamiento del deporte ha sufrido grandes cambios debido a varias razones: el aumento del número de deportes a tratarse en los medios; la trascendencia de los deportes clasificados en el sector de espectáculo; la profesionalización de los deportistas; el interés de las empresas periodísticas en potenciar el espectáculo deportivo; la politización del deporte por gobiernos y políticos; el tratamiento publicitario de clubs y deportistas; el negocio de las apuestas; la proliferación del número de torneos, ligas, campeonatos, juegos, torneos; el asunto del doping, y otros aspectos. Tal cúmulo de situaciones obliga a los periodistas a adoptar nuevos modos y métodos de trabajo, en parte obligados por las empresas periodísticas que imponen una información 
basada en el fomento de las rivalidades entre clubs, federaciones y aficionados y no aficionados, que permita atraer la atención de los clientes y receptores de los medios. La información veraz se ha dejado en manos de unos pocos periodistas que, con el consentimiento de los empresarios periodísticos, juzgan el deporte desde ángulos acordes con la realidad del desarrollo propio del deporte, si bien están condicionados, en sus comentarios, por la política y el negocio comercial y de rendimiento de la empresa periodística. Ello significa que los medios deben contar con mayor número de especialistas en determinados deporte espectáculo. En consecuencia la información deportiva ha perdido el romanticismo de antaño y los artículos y comentarios sobre situaciones producidas en las competiciones y fuera de ellas, así como la realización de buenas entrevistas, ha perdido el favor de los empresarios periodísticos, que buscan, en los aspectos morbosos del deporte, la posibilidad de polémicas entre periodistas, deportistas y aficionados, como método destinado a mantener el interés de los consumidores de la prensa deportiva.

Revista Intercom - Considerando o avanço tecnológico, qual o perfil do jornalista esportivo hoje? As mídias digitais, entre elas, a Internet, por exemplo, mudaram o perfil do "novo" profissional?

Alcoba - La tecnología ha supuesto un gran avance para recortar el tiempo entre el momento de producirse la noticia y su envío al receptor, así como un aumento de los contenidos, produciéndose el curioso caso de que a mayor nivel de información, especialmente desde Internet, se produce una mayor desinformación. El aumento de los receptores de noticias deportivas no ofrecidas en los otros medios de Comunicación, ha precisado de un ejército de especialistas que antes no tenían cabida en los espacios deportivos. Ello significa que el Periodismo deportivo ya no es el enclaustrado en los grandes deportes espectáculo y precisa de periodistas que dominen, por su conocimiento, las reglas y deportistas de los nuevos deportes, máxime cuando ya comienzan a ser considerados como deporte juegos como el poker. En el nivel empresarial periodístico, Internet comienza a ser tratado como una ampliación 
de cuanto se informa en los medios tradicionales, pero todavía sin un perfil propio que supere al periódico, radio o televisión. No obstante, para los receptores de los medios ha supuesto la fórmula de poder polemizar con los periodistas, e incluso denunciar los errores que los periodistas deportivos comenten. Por otro lado, al no tener que limitar el espacio para comunicar los hechos, las noticias pueden ser comentadas con amplitud, lo cual no significa que por esa posibilidad los comentarios promuevan la verdad de los hechos. El Periodismo deportivo, ha pasado de la pluma, tinta y máquina de escribir a poseer unos elementos tecnológicos que le ayudan a trasladar, con mayor rapidez, la noticia al receptor. En este aspecto, el periodista deportivo, o de información general, debe ser educado en el manejo de todos los artilugios tecnológicos, de forma que se convierta en una especie de robot que asiste a la producción de la noticia, la recoge y transmite a su medio en el acto, e incluso pude insertarla en los huecos que en la prensa se dejen libres para su edición. No obstante, pese a estos avances nos encontramos en el inicio de métodos de propagación de la noticia que, indefectiblemente, llevarán a la desaparición del periódico en el futuro. En cuanto a la persona que se dedique al Periodismo, todo girará en su formación sobre uno o varios temas, de los que deberá ser un especialista si desea que su Comunicación responda a lo que demanden los clientes y receptores de los actuales medios y de los que están por venir. De una cosa debemos estar seguros, el periodista, cada vez en mayor medida, tropezará con mayores obstáculos para ofrecer una veraz información, porque los poderes públicos y capitalistas, como ha sucedido siempre, tratarán de someterle a sus intereses. La gran incógnita se encuentra en si las nuevas generaciones de periodistas podrán hacer uso del derecho a la libertad de información, o caerán en las garras de políticos y capitalistas. Internet y otras formas tecnológicas para obtener información, tienen aquí un gran campo a desarrollar, para bien o para mal.

Revista Intercom - O senhor tem afirmado que o desempenho profissional do jornalista esportivo no mundo tem se tornado difícil. Quais são os motivos que dificultam o trabalho desse profissional? 
Alcoba - Es muy difícil ofrecer una respuesta que sirva para el Periodismo deportivo de cada país. Obviamente, mi conocimiento sobre la forma de realizarlo en cada lugar es muy elemental. No obstante, las similitudes de la profesión en todos los paises, una vez que en el deporte y, especialmente los denominados espectáculo, son similares. La profesion de periodista deportivo se ha complicado en exceso por diferentes variables. Enumero: 1. El número de periodistas deportivos ha crecido en exceso y, en la mayorìa de los casos, sin preparación suficiente para entender la problemática en la que se encuentra inmersa la actividad deportiva; 2. La empresas periodísticas, en general, no buscan la información objetiva de las competiciones y hechos deportivos, por mantener que el Perodismo debe amoldarse a los presupuestos económicos de la empresa y buscar, por los derroteros que sean, el interés de los lectores, escuchantes y televidentes; 3. Tanto los deportistas como los clubs del deporte espectáculo, cada vez son más reacios a ser criticados por sus actuaciones, por lo que han reducido la penetración de los periodistas en los clubs y en la vida del deportista profesional, de forma que se ha colocado un obstáculo casi insalvable entre organismos deportivos y deportistas profesionales, y los periodistas; 4 . Hoy todo se mueve bajo la teoría capitalista del mercado de ideas y acciones. El deporte no se ha podido liberar de esa situación - los organismos y clubs organizan sus ruedas de prensa, exponen sus criterios y no responden adecuadamente a las preguntas que se les hacen, o simplemente entrega un dossier en el que manifiestan lo que a ellos les interesa comunicar y que sea divulgado por los medios; 5 . Por su parte, los deportistas profesionales, todos millonarios, ya no ven al periodista como un informador que desea contar cosas de ellos, si no de un enemigo que puede ofertar una visión deformada de ellos - para evitar esas posibles situaciones, se han escudado en las reglas internas de los clubs y en la barrera, muchas veces insalvable, de jefes de prensa y managers, que son quienes responden por ellos; e 6. La paulatina desaparición de amistad personal de los periodistas con los dirigentes o deportistas, ha convertido a los periodistas en suplicadores o mendigadores de unos minutos de acercamiento a 


\section{TENDÊNCIAS DO JORNALISMO ESPORTIVO \\ NA VISÃO DE ANTÔNIO ALCOBA LOPEZ}

los protagonistas del deporte profesional - los tiempos en que los periodistas entrábamos en los vestuarios, acudiamos a los bares o incluso nos acercábamos a los hospitales para preocuparnos por la salud de los deportistas, han finalizado y ahora son estrellas de un firmamento comercial y capitalista que sólo se dejan ver y hablan, cuando los dirigentes, los jefes de prensa, las firmas que publicitan y los managers, lo consideran positivo para la imagen de que quienes se han colocado en el pedestal de falsos dioses.

Revista Intercom - Diante de suas inúmeras obras envolvendo o Jornalismo esportivo, e considerando a difusão deste conhecimento em vários países, inclusive o Brasil, que contribuições o senhor acha que trouxe aos profissionais da área?

Alcoba - En mis obras he trado de ofrecer mi experiencia como periodista deportivo, apoyándola en la investigación que han realizado otros autores. Sin embargo, los posicionamientos son diversos, quizá porque otros investigadores lo eran del ámbito periodístico generalista y no especializado en deporte. Creo que el periodista deportivo no puede desvincularse de los problemas de la sociedad a la que pertenece y por ello debe analizar los problemas del deporte que cada país, en relación a los dos parámetros que siempre cito: la política y el capital, en su sentido de empresa deportiva o industria del deporte. El problema de todo ello es que el deporte, como acción cultural, educativa y formativa, parece no tener nada que ver que con el Periodismo deportivo, pero si el deporte es cultura, no puede ser dejado de los comentarios precisos. Como ya te expuse en mi anterior respuesta, la empresa periodistica no busca la educación y culturizar deportivamente a los aficionados, necesita de ellos como el ejército de soldados que apoyen los enfrentamientos entre clubs y federaciones para que el negocio prospere. E igual situación sucede con la politica, ya que salvo excepciones, el deporte lo utilizan para sus fines, no para educar, sino para utilizarlo propagandísticamente.

Revista Intercom - Em qual mídia (rádio, TV, Jornal ou Internet) o Jornalismo esportivo está mais presente? Alguma mídia se destaca em qualidade na cobertura dos eventos? 
Alcoba - El medio más representativo, al menos por ahora, es la prensa, porque es la encargada de ofrecer opinión, aunque a veces esté manipulada. La Radio y la Televisión son medios puramente comerciales que por su constitución, debida a sus espacios temporales de emisión, se ven obligados a ir directamente a los temas competitivos, y pocas veces a tratar los aspectos conflictivos.

Revista Intercom - O Jornalismo esportivo consegue romper a visão do senso comum?

Alcoba - El Periodismo deportivo, debo insistir en ello, depende de una empresa periodística que busca el beneficio económico y de unas fuerzas políticas que pretenden obtener propaganda por su atención al deporte. Por tanto, los periodistas no siempre pueden expresar lo que quisieran, ya aue, aunque no se crea, la censura existe en mayor o menor medida en los medios Por tanto, muchas de las informaciones responden a los intereses comerciales o políticos, porque el periodista está imposibilitado de ofrecer la realidad. Pero esto sucede en toda clase de Periodismo, hasta en los más democráticos. No olvides que 'busines is busines'.

Revista Intercom - Que análise o senhor faz do Jornalismo esportivo chamado "espetacular"? É uma característica da área esportiva?

Alcoba - El juego o el deporte siempre han sido, en todas las civilizaciones, un espectáculo con los mismos condicionantes que hoy, y manejados por el poder, la religión y la milicia. La Grecia antigua y sus juegos son el mejor ejemplo. Lo que hoy sucede es lo mismo, pero dentro de otras coordenadas influidas por la política y el capital. El que el deporte sea un espectáculo es consustancial con la profesionalización de los deportistas y ello es lo que le ha permitido, como hecho cultural, instalars en entre los hechos más importantes de la reciente historia de la humanidad. Pero, por supuesto, un partido de fútbol entre chicos que sólo se juegan el honor de la victoria, posee tanto o más espectáculo que un partido donde juegue Ronaldo, que por cierto, he leído que ha colgado las botas. 
Revista Intercom - Quais são as particularidades que envolvem uma cobertura esportiva como os Jogos Olimpicos que teremos no Brasil em 2016?

Alcoba - Desde mi experiencia, los Juegos Olímpicos son 28 campeonatos precisados de ser tratados por especialistas. Y aquí reside el problema de los medios de Comunicación, salvo unos pocos medios deportivos no cuentan con especialistas en todo los deportes que en esa competición participan. Es cuando los medios tratan de salir airosos enviando periodistas que deben juzgar deportes que, posiblemente, nunca han seguido. Pero esa circunstancia es la que puede definir a un gran periodista, porque como ya he expuesto en mis libros, los no versados siempre encontrarán colaboración en los propios deportistas, entrenadores y directivos. Y ya que es imposible conocer los reglamentos y los deportistas que participan en ellos, sacar la vena de la experiencia en presenciar deportes espectáculo y sin ser periodista especializado, sí se posee la cualidad de verificar cuando se juega bien o mal.

Revista Intercom - Após os eventos como a Copa do Mundo realizada no ano passado e as Olimpíadas em 2016, a imprensa esportiva do Brasil tende a ser diferente? Em que sentido?

Alcoba - Los periodistas del Brasil son los más capacitados para llevar a efecto un gran trabajo en esos eventos, solo hace falta que no calienten mucho el ambiente y sean objetivos, se gane o se pierda. A fin de cuentas son espectáculos que producen toda clase de sentimientos. Sociológicamente, el fútbol y los Juegos Olímpicos suelen servir para muchas cosas, además de para divertirse. Los gobernantes, los políticos y el capitalismo lo saben, que los periodistas no les hagan el juego, sería muy provechoso para el pueblo. Si quieres documentarte sobre este asunto, te recomiendo leas el libro titulado Fútbol contra el enemigo, de Simon Kuper, título original Fooball Against the Enemy. En el, se describe cuanto de bueno y positivo, como de malo y negativo, puede extraerse del fútbol. El capítulo 17 está dedicado a Brasil, bajo el epígrafe de Pelé, el Malandro. 


\begin{tabular}{|c|c|c|}
\hline \multicolumn{3}{|c|}{ Obras publicadas entre 1972 e 2012 , em Madrid } \\
\hline Título & Ano & Editora \\
\hline 1) ¿Contamos contigo? & 1972 & Editor Gregorio Del Toro \\
\hline $\begin{array}{l}\text { 2) El periodismo deportivo em La } \\
\text { sociedad contemporánea }\end{array}$ & 1980 & $\begin{array}{l}\text { Editorial Deportiva, A.Pila } \\
\text { Teeña }\end{array}$ \\
\hline 3) Deporte y Comunicación & 1987 & $\begin{array}{l}\text { Comunidad Autónoma de } \\
\text { Madrid y Caja Madrid }\end{array}$ \\
\hline $\begin{array}{l}\text { 4) Estructura para uhna enseñanza } \\
\text { teórica de La Educación Fisico Deportiva }\end{array}$ & 1988 & C.O.B \\
\hline 5) Periodismo gráfico: Fotoperiodismo & 1988 & $\begin{array}{l}\text { El Corte Inglés, Coca Cola, } \\
\text { Tabacalera, S.A y ANIGP }\end{array}$ \\
\hline 6) Periodismo gráfico: Fotoperiodismo & 1988 & $\begin{array}{l}\text { Segunda Edición - Editorial } \\
\text { Fragua }\end{array}$ \\
\hline $\begin{array}{l}\text { 7) Especialización: Futuro Del } \\
\text { Periodismo. }\end{array}$ & 1988 & Caja Madrid \\
\hline $\begin{array}{l}\text { 8) Teoria para um nuevo concepto Del } \\
\text { termino doping }\end{array}$ & 1991 & El Corte Inglés \\
\hline $\begin{array}{l}\text { 9) De La Ley. Del Fútbol a } \\
\text { Barcelona } 92\end{array}$ & 1991 & $\begin{array}{l}\text { Editorial Deportiva Esteban } \\
\text { Sanz }\end{array}$ \\
\hline $\begin{array}{l}\text { 10) España em lós Juegos Olímpicos } \\
\text { de Invierno }\end{array}$ & 1992 & COE-CSD \\
\hline $\begin{array}{l}\text { 11) España em lós Juegos Olímpicos } \\
\text { de Verano }\end{array}$ & 1992 & COE-CSD \\
\hline 12) La aventura olímpica & 1992 & Campomanes Libros, S.L. \\
\hline 13) Cómo hacer periodismo deportivo & 1993 & Editorial Paraninfo \\
\hline 14) Asesinato del Asahying Shimpún & 1995 & Editorial Fragua \\
\hline $\begin{array}{l}\text { 15) História de La Tecnología de La } \\
\text { Información (Fotografías) }\end{array}$ & 1997 & Editor Miguel Encinas \\
\hline 16) Montañas Nevadas & $\begin{array}{l}1997 / \\
1998\end{array}$ & $\begin{array}{l}\text { Autor Novela sobre lós } \\
\text { campamentos del Frente de } \\
\text { Juventudes }\end{array}$ \\
\hline 17) La prensa deportiva & 1999 & $\begin{array}{l}\text { Servicio de Publicaciones } \\
\text { de La Universidad } \\
\text { Complutense }\end{array}$ \\
\hline 18) La Guerra NO há terminado & 2000 & $\begin{array}{l}\text { Autor (Investigación sobre } \\
\text { la política española }\end{array}$ \\
\hline $\begin{array}{l}\text { 19) Historia de La Tecnologia de La } \\
\text { Información Impresa (II) }\end{array}$ & 2001 & Fragua \\
\hline 20) Enciclopedia del Deporte & 2001 & $\begin{array}{l}\text { Librerias deportivas Esteba } \\
\text { Sanz }\end{array}$ \\
\hline $\begin{array}{l}\text { 21) Barcelona 93. Lós Juegos del } \\
\text { desenfreno }\end{array}$ & 2002 & $\begin{array}{l}\text { Servício de Publicaciones de } \\
\text { Ciencias de La Información }\end{array}$ \\
\hline $\begin{array}{l}\text { 22) Auge y ocaso de El Frente de } \\
\text { Juventudes }\end{array}$ & 2002 & Editorial San Martín \\
\hline
\end{tabular}




\begin{tabular}{|l|c|l|}
\hline Título & Ano & Editora \\
\hline $\begin{array}{l}\text { 23) Un muerto y ocho vivos (Rostros } \\
\text { de La Trasición) }\end{array}$ & 2003 & Editorial San Martín \\
\hline 24) El reportage fotográfico & 2004 & Autor \\
\hline $\begin{array}{l}\text { 25) Los chistes y cosas de el Frente } \\
\text { de Juventudes Jesús Fragoso del Toro } \\
\text { "Chuchi" Recopilación de Antonio } \\
\text { Alcoba }\end{array}$ & 2004 & \\
\hline $\begin{array}{l}\text { 26) Hockey Catálogo de La exposición } \\
\text { de fotografias de Antonio Alcoba. }\end{array}$ & 2004 & \\
\hline 27) Periodismo Deportivo & 2005 & Editorial Sintesis \\
\hline $\begin{array}{l}\text { 28) El fútbol español de mediados del } \\
\text { siglo XX (Fotografias y texto) }\end{array}$ & 2005 & $\begin{array}{l}\text { Librerías Deportivas } \\
\text { Esteban Sanz }\end{array}$ \\
\hline $\begin{array}{l}\text { 29) iQuo Vadis deporte? } \\
\text { 30) Juegos e travesuras del lós niños } \\
\text { de La posguerra }\end{array}$ & 2012 & $\begin{array}{l}\text { Librerías Deportivas } \\
\text { Esteban Sanz }\end{array}$ \\
\hline
\end{tabular}

\section{Marli Hatje (autora da entrevista)}

Jornalista e professora de Educação Física. Docente do Departamento de Métodos e Técnicas Desportivas do Centro de Educação Física e Desportos da Universidade Federal de Santa Maria. Coordenadora do Núcleo de Estudos e Pesquisas em Comunicação e Mídia na Educação Física e Esporte (NEPCOMEFE). Líder de Grupo de Pesquisa no CNPQ, desde 2007 na mesma área. Co-fundadora do GT Mídia e Esporte, da Intercom, em 1996, em LondrinaPR.E-mail: hatjehammes@yahoo.com.br 